\title{
Development and characterization of DNA sequence OmyPg associated with the sex chromosomes in rainbow trout
}

\author{
PATRICIA ITURRA* $\dagger$, MARK BAGLEY $\$$, NORA VERGARA $\dagger$, \\ PAULA IMBERT $\uparrow \&$ JUAN F. MEDRANO \\ $\dagger$ Facultad de Medicina, Programa de Genética Humana, ICBM, Universidad de Chile, Independencia 1027, Santiago, \\ Chile and $\ddagger$ Department of Animal Science, University of California, Davis, CA 95616-8521, U.S.A.
}

\begin{abstract}
This work describes the construction and characterization of a sequence characterized amplified DNA region (SCAR DNA), designated $O m y P 9$, that was derived from a RAPD marker associated with the sex chromosomes in rainbow trout. A $R s a \mathrm{I}$ restriction fragment length polymorphism in OmyP9 identifies variants A, B and C. We found six OmyP9 variant phenotypes $-\mathrm{A}, \mathrm{B}, \mathrm{C}, \mathrm{AB}, \mathrm{BC}$ and $\mathrm{ABC}$, in 186 individuals of seven different rainbow trout strains. The patterns of inheritance of OmyP9 in 139 fingerlings from 10 crosses of three strains of rainbow trout were studied. The males had a greater representation of the A variant (93.3\%) suggesting an association with the $\mathrm{Y}$ chromosome. All male fingerlings analysed inherited the A variant from their male parents. These results support the hypothesis that $O m y P 9$ is located on the sex chromosomes of rainbow trout, and that for the males studied the A variant is located on the $\mathrm{Y}$ chromosome in a region close to sex determinants and/or in a sector where the genetic recombination between $\mathrm{X}$ and $\mathrm{Y}$ is restricted. The present evidence also supports our previous hypothesis that $O m y P 9$ is organized as a tandem repeated sequence in the sex chromosomes of rainbow trout. We feel that the OmyP9 RsaI marker can be used for sex identification in crosses where it is possible to determine the phenotype of the parents.
\end{abstract}

Keywords: polymorphism, rainbow trout, SCAR, sex marker.

\section{Introduction}

Karyotype studies in teleost fishes have revealed that in most species sex chromosomes are not cytologically differentiated. In these species, males have been typically identified as the heterogametic sex by the analysis of crosses with hormonally sex-reverted individuals (Kirpichnikov, 1981). In salmonid species, only lake trout (Salvelinus namaycush), rainbow trout (Oncorhynchus mykiss) and sockeye salmon (O. nerka) males present morphologically differentiated heterochromosomes (Hartley, 1987). Molecular analysis has provided a useful tool to distinguish markers associated with these chromosomes in salmonids. In chinook salmon (O. tshawytscha) and in lake trout, moderately repetitive DNA sequences have been identified, which in some cases are differentially represented on the $\mathrm{Y}$ chromosome in relation to the other chromosomes, and/or are present with a specific organization on the Y chromosome (Devlin et al., 1991, 1998; Reed \& Phillips, 1995).

*Correspondence. E-mail: piturra@machi.med.uchile.cl
Additionally, two growth hormone genes, a functional GH-2 and a pseudogene, have been identified in the respective sex chromosomes of coho and chinook salmon (Du et al., 1993; Forbes et al., 1994).

In the rainbow trout, O. mykiss, it is thought that sex chromosomes could be in an initial stage of differentiation. In males, $\mathrm{X}$ and $\mathrm{Y}$ chromosomes are subtelocentric, differing slightly in the size of their short arms (Thorgaard, 1977, 1983). Besides their morphological similarity, the sex chromosomes of rainbow trout conserve a high degree of genetic homology as is suggested by viability and fertility studies of YY male individuals obtained by androgenesis or sex-reversion assays (Parsons \& Thorgaard, 1985; Chevassus et al., 1988) as well as from evidence of the meiotic X-Y chromosomal pairing during spermatogenesis (Oliveira et al., 1995). Two allozyme loci with partial sex linkage have been described in rainbow trout (Allendorf et al., 1994). Furthermore, the detailed linkage map of rainbow trout reported by Young et al. (1998) shows a set of molecular markers linked to sex. The genetic recombination observed by these authors confirms the 
genetic similarity among the sex chromosomes of rainbow trout. Thorgaard $(1977,1983)$ suggested the existence of an intraspecific polymorphism in the sexchromosome pair of rainbow trout, in which males of some populations show no evidence of heteromorphic chromosomes.

We have carried out studies to identify molecular markers for sex chromosome in rainbow trout. By combining the RAPD method with bulked segregant analysis, using both male and female rainbow trout DNA pools, we identified a RAPD marker $(O P-P 09)$ which predominantly generated a male specific $405 \mathrm{bp}$ fragment (Iturra et al., 1998). This male RAPD fragment was cloned, sequence and converted into a SCAR (Sequence Characterized Amplified Region) (Paran \& Michelmore, 1993). In an earlier study we reported the chromosomal localization of this SCAR DNA fragment using fluorescent in situ hybridization, which revealed defined signals on sex chromosomes in rainbow trout (Iturra et al., 1998). Further molecular and genetic characterization of this marker will aid our ongoing studies on the mechanisms of sex determination in rainbow trout and the evolution and differentiation of salmonid sex chromosomes, as well as for the development of useful molecular markers for early sex identification in this species.

The aim of this paper is to describe the construction and characterization of SCAR DNA fragment referred to as OmyP9. We show the existence of different variants of this SCAR in males and females of different rainbow trout strains and through analysis of several families establish that this marker is inherited in a sexlinked manner.

\section{Materials and methods}

\section{Origin of specimens}

Sexually mature adult specimens of rainbow trout from Mount Lassen Trout Farm, California were used to identify a RAPD marker that generated a predominantly male polymorphism (Iturra et al., 1998). This RAPD marker was used to develop a RAPD-SCAR marker that was tested in different rainbow trout strains and coho salmon farms in different regions of Chile. Rainbow trout samples were collected from Scottish and Americana strains (Rio Blanco-UCV Hatchery, Región V), and Cofradex, Donaldson, Avdadlaks and Steelhead strains (Piscícola Huililco Ltda., Pucón, and Región IX). Coho salmon samples were collected from three sites in Región X, Chile (Piscicultura Dr Shiraishi, Centro de Mejoramiento Genético IFOP and Acuicultura Chalhuaco S. A., Chiloe).
Eight individual crosses were made from individuals of the Scottish strain that had previously been genotyped for the $O m y P 9$ variant phenotypes (Table 2). One cross was made in the Cofradex and in the Steelhead strains. Fertilization was carried out according to Colihueque et al. (1992). The crosses were made at the respective hatcheries mentioned above. Each progeny family was reared until the fingerlings were old enough to determine their sex by gonadal examination at approximately 6 months of age. Each fingerling was dissected, the gonads removed and fixed in $50 \%$ acetic acid for at least one hour. The sex was verified by histological analysis of gonadal tissue, using the squash method, with a Nikon phase contrast light microscope at low magnification. Blood samples for DNA extraction were obtained from all the parental fish at the time of fertilization.

\section{DNA extraction}

For each previously anaesthetized specimen, either a blood sample was taken from the lateral vein and stored in 5-mL EDTA-vacutainer tubes, or a small piece of dorsal fin was clipped and maintained in $100 \%$ ethanol. DNA was extracted from red blood cells by digestion with proteinase $\mathrm{K}$, followed by phenol-chloroform extraction and ethanol precipitation. DNA extraction from small fins was performed with $5 \%$ chelex (Bio-Rad Laboratories, Hercules, California) as described by Van Eenennaam et al. (1996). The supernatant from the chelex extraction was diluted 1:5 in $0.1 \times$ Tris-EDTA for use in PCR reactions.

\section{Development of a SCAR marker}

An individual 405 bp male-specific band was observed when male and female DNA from the Mount Lassen rainbow trout strain was amplified with RAPD primer OP-P09 (GTGGTCCGCA) (Operon Technologies 10-mer kit $\mathrm{P})$ and electrophoresed on a $1.8 \%$ agarose gel (Iturra et al., 1998). A sampled plug of this DNA fragment was picked from an agarose gel with a sterile narrow-bore pipette tip, and re-amplified using primer OP-P09 with the same PCR conditions used for the original RAPD reactions. The re-amplification product was resolved on a $1.5 \%$ agarose gel and the amplified band was excised from the gel and purified using QIAquick Gel extraction kit (Qiagen). The product was cloned into the TA-vector (Invitrogen Corp.) using protocols provided by the manufacturer. Sequencing was performed using fluorescent dyes with an automated ABI 377 sequencer. Two SCAR primers were produced within the sequenced male fragment, P922F (5'-GCATTGTGCTGGAGATCA-3') and 
P922R (5'-TGCCACCGCCTACTATCC-3'), which amplified a single band of 370-bp (SCAR P922). We utilized Vectorette-PCR (Arnold \& Hodgson, 1991) in order to amplify unknown sequences external to the $5^{\prime}$ and $3^{\prime}$ ends of the fragment. We extended the SCAR P922 fragment by approximately $291 \mathrm{nt}$ and $277 \mathrm{nt}$ from the $5^{\prime}$ and $3^{\prime}$ ends, respectively. The resulting fragment of $938 \mathrm{bp}$ was partially sequenced and a new pair of primers was synthesized (P9For, 5'-TGCATTCCACTTCTTCTCGTT-3'; and P922R2, 5'-GACGTCAAAGGTTGCTGGTT-3'). These primers amplified a fragment with size polymorphisms of 899,894 and $840 \mathrm{bp}$. This fragment is referred to as Oncorhynchus mykiss-P9, OmyP9.

PCR conditions using primers P9For and P922R2 and internal primers $(\mathrm{P} 922 \mathrm{~F}-\mathrm{P} 922 \mathrm{R})$ were: $1 \times \mathrm{PCR}$ buffer, $100 \mu \mathrm{M}$ of each dNTP, $2 \mathrm{~mm} \mathrm{MgCl}_{2}, 0.3 \mu \mathrm{M}$ of each primer, 0.5 U Taq DNA polymerase (GIBCO) and $30 \mathrm{ng}$ of template DNA. PCR amplifications were performed using an MJ Research PTC-100 96-V thermal cycler. The amplification profile was $94^{\circ} \mathrm{C}$ for $2 \mathrm{~min}$, followed by 30 cycles of $94^{\circ} \mathrm{C}(45 \mathrm{~s}), 59^{\circ} \mathrm{C}(45 \mathrm{~s})$ and $72^{\circ} \mathrm{C}$ (55 s, last cycle $5 \mathrm{~min}$ ). PCR products were analysed by electrophoresis on $1.5 \%$ ethidium-bromide stained agarose gels.

\section{Restriction enzyme analysis}

To identify restriction fragment length polymorphisms (RFLPs) 5-6 $\mu \mathrm{L}$ of OmyP9 PCR product was digested with restriction enzymes AciI, AvaII, HaeIII, HinfI and RsaI. Enzyme digestions were carried out in a volume of $10 \mu \mathrm{L}$ following the protocol suggested by the enzyme manufacturer (New England Biolabs). Digestion products were separated by electrophoresis on $1.5 \%$ ethidium-bromide stained agarose gels.

\section{Results}

\section{Polymorphisms of fragment OmyP9 in rainbow trout}

The SCAR OmyP9 amplifies in both sexes in rainbow trout with size polymorphisms of 899,894 and $840 \mathrm{bp}$ (GenBank Accession No. AF323613). To investigate whether OmyP9 presented sequence polymorphisms, PCR products of both males and females were digested with various restriction endonucleases. Endonuclease $R s a$ I clearly differentiated two OmyP9 variants of the larger 899 and 894 bp fragments. The 894 bp variants, referred to as variant $\mathrm{A}$, had two restriction sites for this enzyme, at sequence positions 441 and 555, which generated three bands of 441, 114 and $339 \mathrm{bp}$. The 899 bp variant, referred to as variant $\mathrm{B}$, had a single restriction site for $R s a \mathrm{I}$ at sequence position 555, which resulted in two bands of 555 and $344 \mathrm{bp}$. The third OmyP9 variant, referred to as variant $\mathrm{C}$, originated from the smaller fragment of $840 \mathrm{bp}$. Variant $\mathrm{C}$ had one restriction site for $R s a \mathrm{I}$ at position 501, resulting in two bands of 501 and $339 \mathrm{bp}$.

OmyP9 was amplified with external and/or internal primers and subjected to digestion with RsaI in 186 individuals of seven different rainbow trout strains, six of which are cultivated in Chile. Table 1 shows the observed $R s a \mathrm{I}$ restriction phenotypes of $O m y P 9$ in males and females. We have identified six different restriction phenotypes in relation to the $O m y P 9$ variants: A, B, C, $\mathrm{AB}, \mathrm{BC}$ and $\mathrm{ABC}$ (Figs 1 and 2). As shown in Table 1, in all strains, variant $\mathrm{A}$ is observed predominantly in males. The B and BC phenotype are only found in males of the Americana strain. Until now, we have not observed males with the $\mathrm{C}$ phenotype. In four individuals, the more complex phenotype $\mathrm{ABC}$ was found in which the three variants were observed in the same

Table 1 Observed phenotypes of OmyP9 variants A, B and C in male and female individuals from different strains of rainbow trout

\begin{tabular}{|c|c|c|c|c|c|c|c|c|c|c|c|c|c|}
\hline \multirow[b]{2}{*}{ Strain } & \multicolumn{6}{|c|}{ Male phenotypes } & \multicolumn{7}{|c|}{ Female phenotypes } \\
\hline & A & $\mathrm{AB}$ & $\mathrm{ABC}$ & B & $\mathrm{BC}$ & $n$ & A & $\mathrm{AB}$ & $\mathrm{ABC}$ & B & $\mathrm{BC}$ & $\mathrm{C}$ & $n$ \\
\hline Americana & & 13 & 3 & 5 & 3 & 24 & & 6 & 1 & 5 & 9 & & 21 \\
\hline Cofradex & 6 & 10 & & & & 16 & 1 & 1 & & 10 & & 2 & 14 \\
\hline Steelhead & 4 & 7 & & & & 11 & & 5 & 3 & 2 & & 1 & 11 \\
\hline Donaldson & & 6 & & & & 6 & & & & 10 & & 1 & 11 \\
\hline Scottish & 2 & 16 & & & & 18 & 2 & 3 & & 7 & 6 & 1 & 19 \\
\hline Avdadlaks & 2 & 4 & & & & 6 & 2 & 2 & & & & 1 & 5 \\
\hline Mount Lassen & & 11 & 1 & & & 12 & & & & 6 & 2 & 4 & 12 \\
\hline Total & 14 & 67 & 4 & 5 & 3 & 93 & 5 & 17 & 4 & 40 & 17 & 10 & 93 \\
\hline
\end{tabular}

$n$, the total number of individuals of each strain and sex. 


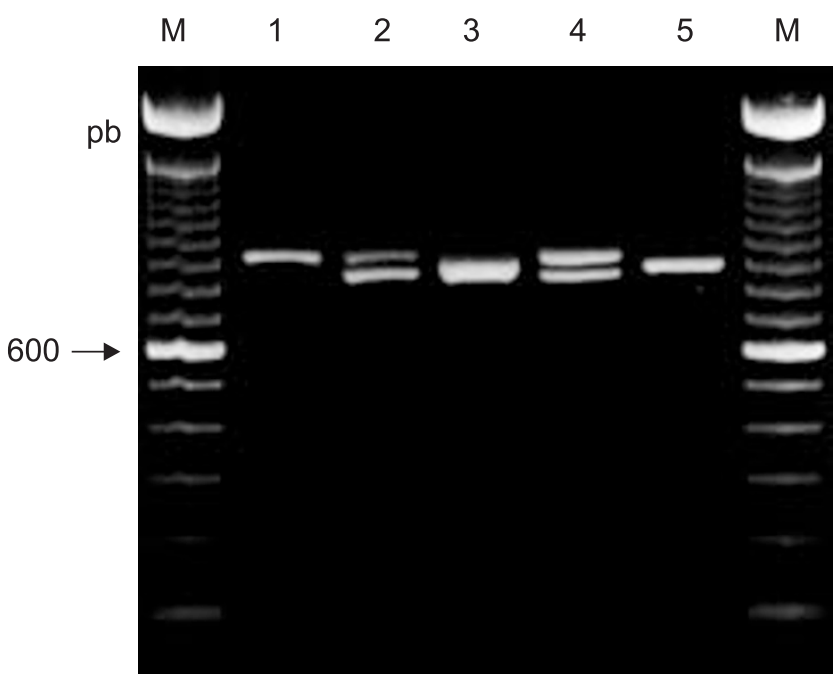

Fig. 1 Agarose gel separation (1.5\%) of SCAR OmyP9 PCR amplification products with primers P9For and P922R2 in rainbow trout (lanes 1-4) and coho salmon (lane 5). Lane 1: $O m y P 9$ amplification products of 894 and 899 bp; lanes 2 and 4: OmyP9 894/899-840 bp; lane 3: OmyP9 variant C (840 bp); and lane 5: fragment amplified in coho salmon with primers P9For and P922R2 of OmyP9. M: 100 bp ladder size marker.

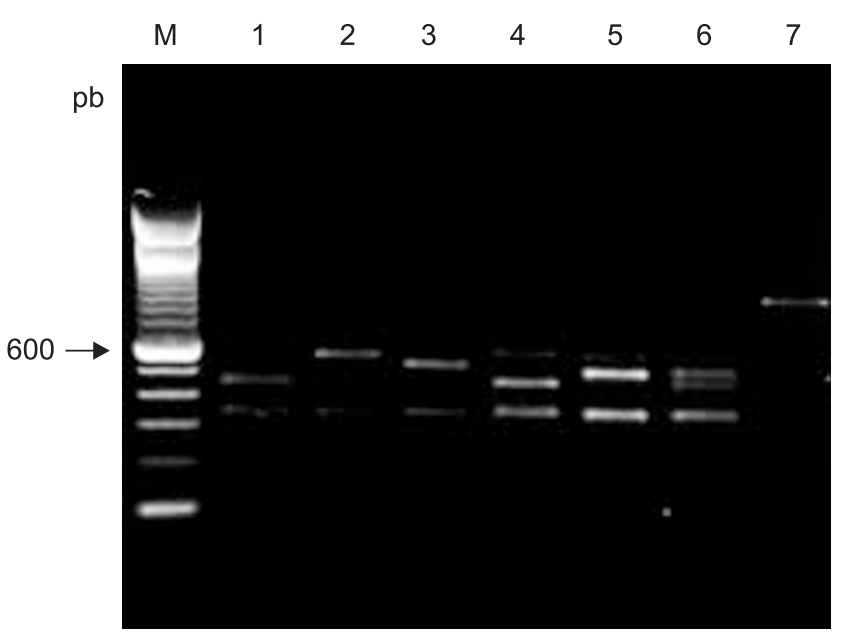

Fig. 2 Agarose gel separation (1.5\%) of RsaI-RFLP of SCAR OmyP9 in rainbow trout (lanes 1-6). Lanes 1, 2 and 3: OmyP9 variants (phenotypes) A, B and $\mathrm{C}$, respectively; lane 4: phenotype $\mathrm{AB}$; lane 5: phenotype $\mathrm{BC}$; lane 6: phenotype $\mathrm{ABC}$; and lane 7: fragment amplified in coho salmon and digested with RsaI. M: 100 ladder size marker.

animal. In females, phenotypes were more diverse, with $\mathrm{B}$ and $\mathrm{BC}$ being the most frequent. Variant $\mathrm{A}$ was only present in $28 \%$ of females. Females carrying the ABC phenotype were observed in two strains.

Amplified fragments were sequenced from two rainbow trout specimens for each A, B and C phenotype.

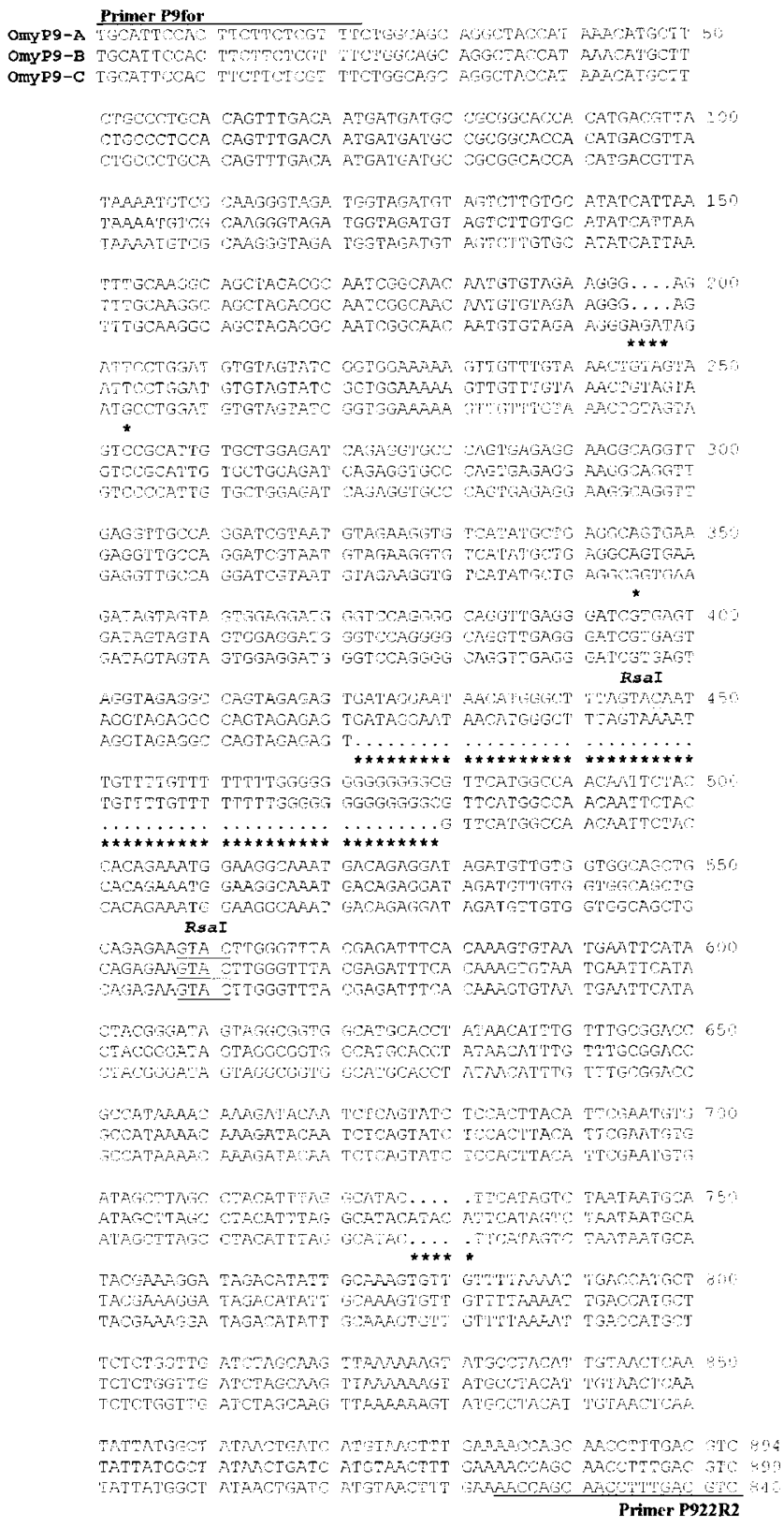

Fig. 3 DNA sequence of rainbow trout RAPD-SCAR OmyP9 (GenBank Accession No. AF323613) variants A (894 bp), B (899 bp) and C (840 bp). Base mismatches and alignment gaps are marked with an asterisk (*). Position of primers P9For and P922R2, and of $R s a \mathrm{I}(\mathrm{GT} / \mathrm{AC}$ ) restriction site are underlined. The $R s a \mathrm{I}$ restriction site at sequence position 441 is specific for variant A.

Sequences for each of the variants are very similar (Fig. 3). Variant $\mathrm{C}$ has a deletion of $58 \mathrm{bp}$ at position 420 with respect to $\mathrm{A}$ and $\mathrm{B}$. There is high sequence identity (98\%) between $\mathrm{A}$ and $\mathrm{B}$, a slightly lower sequence identity between $\mathrm{A}$ and $\mathrm{C}(89.5 \%)$ and a low sequence identity between B and C $(88 \%)$. The restriction poly- 
morphism which distinguishes variant $\mathrm{A}$ from $\mathrm{B}$ is due to a substitution (transversion) in base pair four in the recognition site for $R s a \mathrm{I}$ (GTAC to GTAA). This site is absent from variant $\mathrm{C}$ because it is located in the deleted region which characterizes this fragment. Variants $\mathrm{B}$ and $\mathrm{C}$ contain insertions and deletions in different regions of the sequences, which may be useful in designing variant-specific primers for each of them. Sequences similar to $O m y P 9$ were not detected in Genbank.

To investigate if $O m y P 9$ is present in another species of salmonid we searched for the presence of $O m y P 9$ or related sequences in coho salmon. All primer sets of $O m y P 9$ were tested on 45 samples from both sexes of this species. The product size of the amplified PCR fragment with the external primers (P9For-P922R2), and the internal primers (P922F-P922R) were of comparable size to $O m y P 9$. Restriction patterns similar to rainbow trout were also observed when digesting coho salmon male and female amplification products with endonucleases $\operatorname{Hinf} \mathrm{I}$, $H a e I I I$ and $A c i$ I. Unlike the polymorphism observed for $O m y P 9$ in rainbow trout with $R s a \mathrm{I}$, there are no restriction sites for this enzyme in coho salmon (Figs 1 and 2).

\section{Mode of inheritance of OmyP9 SCAR}

$O m y P 9$ was amplified and digested with $R s a \mathrm{I}$ in progeny of rainbow trout families in order to establish the pattern of inheritance of the different variants. Table 2 shows the results of segregation patterns for families derived from individual crosses of parental phenotypes classified as OmyP9 variants A, B and C. The study included 139 fingerlings of between 140 and 200 degrees/days from 10 crosses of three different strains of rainbow trout. A total of 139 fingerlings were sexed by gonadal histological

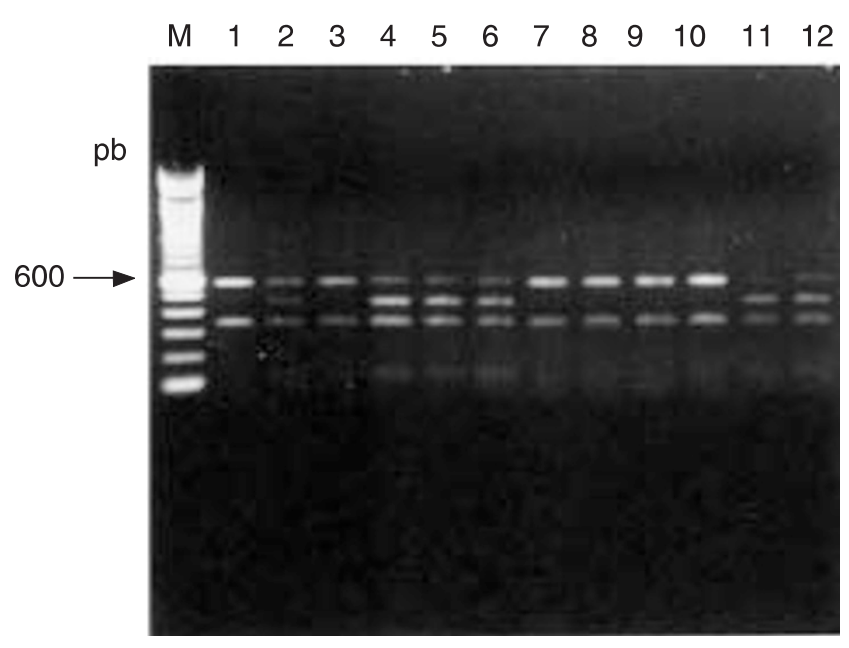

Fig. 4 Agarose gel separation (1.5\%) of RsaI RFLPs for SCAR OmyP9 in a rainbow trout family. Lane 1: B phenotype of female parent; Lane 2: AB phenotype of male parent; lanes 4, 5, 6, 11 and 12: male progeny with $\mathrm{AB}$ phenotype; lanes 3, 7, 8, 9 and 10: female progeny with B phenotype. M: $100 \mathrm{bp}$ ladder size marker.

analysis. In nine crosses, the parental male had the AB phenotype and only in one cross (cross 6), the male parent had the A phenotype. The restriction patterns of some of the specimens analysed in the $F_{1}$ of cross 4 are shown in Fig. 4. Considering all 10 families, segregation of $\mathrm{A}, \mathrm{B}$ and $\mathrm{C}$ fragments in the progeny suggests that OmyP9 is located in the sex chromosomes. The fragment present in the father was inherited in 78 males. This fragment was not observed in any of $61 \mathrm{~F}_{1}$ females. This result suggests that males carrying variant $\mathrm{A}$ have OmyP9 located on the $\mathrm{Y}$ chromosome, in a region close

Table 2 Segregation analysis of 139 rainbow trout progeny produced from individual crosses of parents classified for $O m y P 9$ variants A, B and C

\begin{tabular}{|c|c|c|c|c|c|c|c|c|c|}
\hline \multirow[b]{3}{*}{ Strain } & & & & \multicolumn{6}{|c|}{ Progeny } \\
\hline & \multicolumn{3}{|c|}{ Parental phenotypes } & \multicolumn{3}{|c|}{ Males } & \multicolumn{2}{|c|}{ Females } & \multirow[b]{2}{*}{ Tota } \\
\hline & Cross & Male & Female & A & $\mathrm{AB}$ & $\mathrm{ABC}$ & B & $\mathrm{BC}$ & \\
\hline \multirow[t]{8}{*}{ Scottish } & 1 & $\mathrm{AB}$ & B & 4 & 5 & & 5 & & 14 \\
\hline & 2 & $\mathrm{AB}$ & B & & 9 & & 9 & & 18 \\
\hline & 3 & $\mathrm{AB}$ & B & & 4 & & 8 & & 12 \\
\hline & 4 & $\mathrm{AB}$ & B & & 9 & & 10 & & 19 \\
\hline & 5 & $\mathrm{AB}$ & B & 4 & 2 & & 5 & & 11 \\
\hline & 6 & A & $\mathrm{BC}$ & & & 3 & 1 & 3 & 7 \\
\hline & 7 & $\mathrm{AB}$ & $\mathrm{BC}$ & & 6 & 1 & 1 & 6 & 14 \\
\hline & 8 & $\mathrm{AB}$ & $\mathrm{C}$ & & 4 & 5 & 2 & 1 & 12 \\
\hline Donaldson & 9 & $\mathrm{AB}$ & B & & 9 & & 2 & & 11 \\
\hline Steelhead & 10 & $\mathrm{AB}$ & B & & 13 & & 8 & & 21 \\
\hline
\end{tabular}


to the sex determination locus and/or in a sector where the genetic recombination between $\mathrm{X}$ and $\mathrm{Y}$ is restricted.

\section{Discussion}

The RAPD marker $O P-P 09$, which is associated with the sex chromosomes of rainbow trout and amplifies preferentially in males (Iturra et al., 1998), was converted into SCAR marker OmyP9. Thus, OmyP9 is a more practical genetic marker for studying the sex chromosomes of rainbow trout, since SCARs do not have the problems of sensitivity and repeatability of RAPD markers. OmyP9 amplifies in males and females of rainbow trout, confirming our previous observations which showed FISH-hybridization of this SCAR to the sex chromosomes of rainbow trout (Iturra et al., 1998). This finding is also in agreement with previous studies that indicate high genetic similarity between the conserved $\mathrm{X}$ and $\mathrm{Y}$ chromosomes of rainbow trout (Thorgaard, 1977; Allendorf et al., 1994; Oliveira et al., 1995; Young et al., 1998).

Polymorphism analysis of $O m y P 9$ in the different strains of rainbow trout showed that none of the variants $\mathrm{A}, \mathrm{B}$ or $\mathrm{C}$ were strictly associated with male and female of the studied samples. However, the greater representation of the A variant in males $(93.3 \%)$, suggests an association with the $\mathrm{Y}$ chromosome. The genetic analyses of different strains support this hypothesis. Only the Americana strain possessed some males that did not carry the A variant suggesting this variant does not exist in perfect cis-phase linkage with the sex locus in all populations. Another hypothesis could be the existence of two Y chromosome types in rainbow trout (Thorgaard, 1977, 1983; Colihueque et al., unpublished data). Distribution differences of the different phenotypes among the studied strains may be due to reduced sample size of some of them. However, this difference is not surprising, since it is well known that cultivated rainbow trout strains have large genetic differences (Allendorf \& Phelps, 1981). In general, the rainbow trout strains studied correspond to different genetic stocks that have been artificially selected for important production traits. For example, studies of population genetic variability with isoenzyme markers in the Americana strain suggest that a strong founder event occurred in this strain (Winkler et al., 1995).

The RsaI RFLP of OmyP9 in rainbow trout allowed us to study its mode of inheritance by analysing the segregation in several families from several strains. These results provided strong evidence that the SCAR $O m y P 9$ is located on the sex chromosomes of rainbow trout and that for the males studied, the A variant is located on the Y chromosome, possibly close to the sex determination locus and/or in a region where genetic recombination is restricted. To our knowledge, the OmyP9 sequence is the first sequence to be described which shows an association to the $\mathrm{Y}$ chromosome in rainbow trout. OmyP9 is located in the medial region of the long arm of the sex chromosomes in rainbow trout as is shown by FISH (Iturra et al., 1998). Identification by in situ hybridization of the location of this SCAR in coho salmon chromosomes could be useful for identifying the sex chromosomes of this species (De La Fuente et al., 1999).

The most accepted hypothesis regarding the origin of sex chromosomes in vertebrates is that of Ohno (1967), who hypothesized that heterochromosomes have originated from homomorphic chromosomes in which, by mechanisms not yet understood, genetic recombination during meiosis became restricted in the sex-determining information region. Differentiation of the $\mathrm{Y}$ chromosome is accompanied by molecular changes in DNA as well as in chromosome architecture. These changes may become fixed in an accumulative process, associated with restriction of the genetic interchange between the XY pair (Charlesworth, 1978, 1991). Evidence of differentiation at a molecular level between sex chromosomes $(\mathrm{X} / \mathrm{Y}$ or $\mathrm{Z} / \mathrm{W})$ has been obtained in fish, including salmonids (Devlin et al., 1991, 1998; Nakayama et al., 1994; Reed \& Phillips, 1995; Matsuda et al., 1997, 1998). Generally, this evidence corresponds to anonymous repeated sequences, although it has been reported that one of the loci of the $5 \mathrm{~S}$ ribosomal genes is physically located on the $\mathrm{X}$ chromosome of rainbow trout (Moran et al., 1996). Previous in situ hybridization studies using SCAR OmyP9 have suggested that this sequence is tandemly repeated with a different number of copies and/or a different organization between the sex chromosomes of rainbow trout (Iturra et al., 1998). The results of the inheritance studies for $O m y P 9$ variants in some of the analysed crosses are compatible with this hypothesis. The progeny phenotypes observed for crosses 1 and 5 (Table 2), where males $(n=8)$ with the A phenotype were observed, may be explained if both parental females possessed the B fragment in only one of their two $\mathrm{X}$ chromosomes. $\mathrm{BC}$ and $\mathrm{ABC}$ phenotypes observed in crosses 6,7 and 8 could be explained by a model, in which OmyP9 may form part of a tandem repeat, but these tandem sequence repeats may not be strictly homogeneous. The results of cross 8 , in which an $\mathrm{AB} \times \mathrm{C}$ cross produce male progeny with the $\mathrm{ABC}$ phenotype can be explained if we consider that the $A B$ male phenotype was produced by the presence of $\mathrm{AB}$ on the $\mathrm{Y}$ chromosome, and by $\mathrm{B}$ on the $\mathrm{X}$ chromosome. The female parent would have possessed the $\mathrm{C}$ sequence on one of the $\mathrm{X}$ chromosomes. This organizational model of A and B variants in the $\mathrm{Y}$ chromosome could also be valid for all other males used in this study, 
though this cannot be proven at this level of analysis. The possible repeated structure of $O m y P 9$ may allow unequal crossing-over events between the sex chromosomes, which could also explain the results of some crosses made (crosses 6,7 and 8), as well as the existence of various phenotypes in the populations studied. With the present data set it is not possible to establish a single model to explain the genomic organization of the $O m y P 9$ sequence, mainly due to its repeated nature (Iturra et al., 1998). We cannot discard the possibility that $O m y P 9$ or related sequences are present in other regions of the genome, considering that it has been suggested that salmonids are tetraploid species where the process of diploidization is still incomplete (Hartley, 1987). It is necessary to design new crosses and to carry out more studies to elucidate the genomic structure of the sex marker OmyP9. This marker should prove useful to identify the genetic sex of rainbow trout progeny in crosses where it is possible to determine the $R s a \mathrm{I}$ restriction phenotype of the parents.

\section{Acknowledgements}

This work was supported by grant Fondecyt 1970421 to P.I. We gratefully acknowledge the technical assistance provide by Alma Islas at U. C. Davis. We thank Natalia Lam for her suggestions to the manuscript. We also thank Rio Blanco-UCV Hatchery, Piscícola Huililco Ltda., Piscicultura Dr Shiraishi, Centro de Mejoramiento Genético IFOP, Acuicultura Chalhuaco S.A., Chile and Mount Lassen Trout Farm, Redbluff, California for providing fish samples.

\section{References}

ALlENDORF, F. W. AND PHELPS, S. R. 1981. Isozymes and the preservation of genetic variation in salmonid fishes. Ecol. Bull., 34, 37-52.

ALlendorF, F. W., GELlMAN, W. A. AND THORGAARD, G. H. 1994. Sex-linkage of two enzymes loci in Oncorhynchus mykiss (rainbow trout). Heredity, 72, 498-507.

ARNOLD, C. AND HODGSON, I. J. 1991. Vectorette PCR: a novel approach to genomic walking. PCR Meth. Applications, 1, 39-42.

CHARlesworth, B. 1978. Model for evolution of Y chromosomes and dosage compensation. Proc. Natl. Acad. Sci., 75, 5618-5622.

CHARLESWORTH, B. 1991. The evolution of sex chromosomes. Science, 251, 1030-1033.

Chevassus, B., DevauX, A., ChOURRout, D. AND JALABERT, B. 1988. Production of YY rainbow trout males by selffertilization of induced hermaphrodites. J. Hered., 79, 89-92. COlihueque, N., ITURRA, P., DiAZ, N., Veloso, A. ET AL. 1992. Karyological analysis and identification of heterochromosomes in experimental gynogenetic offspring of rainbow trout (Oncorhynchus mykiss, Walbaum). Rev. Brasil. Genet., 15, 535-546.

DE LA FUENTE., M., VERGARA, N., LAM, N., MEDRANO, J. F. ET AL. 1999. Búsqueda de los cromosomas sexuales en salmón coho (Oncorhynchus kisutch) mediante FISH. Biol. Res., 32, $\mathrm{R}-212$.

DEVLIN, R. H., MCNEIL, B. K., GROVES, T. D. AND DONALDSON, E. M. 1991. Isolation of a Y-chromosomal DNA probe capable of determining genetic sex in chinook salmon (Oncorhynchus tshawytscha). Can. J. Fish. Aquat. Sci., 48, 1606-1612.

DEVlin, R. H., STONE, G. W. AND SMAilus, D. E. 1998. Extensive direct-tandem organization of a long repeat DNA sequence on the Y chromosome of chinook salmon (Oncorhynchus tshawytscha). J. Mol. Evol., 46, 277-287.

DU, S. H. J., DEVliN, R. H. AND HEW, C. H. L. 1993. Genomic structure of growth hormone genes in chinook salmon (Oncorhynchus tshawytscha): presence of two functional genes, GH-I and GH-II, and a male-specific pseudogene, gh-४. DNA Cell Biol., 12, 739-751.

FORBES, S. H., KNUDSEN, K. L., NORTH, T. W. AND ALLENDORF, F. W. 1994. One of two growth hormone genes in coho salmon is sex-linked. Proc. Natl. Acad. Sci., 91, 1628-1631.

HARTLEy, s. 1987. The chromosomes of salmonid fishes. Biol. Rev., 62, 197-214.

ITURRA, P., MEDRANO, J. F., BAGLEY, M., LAM, N. ET AL. 1998. Identification of sex chromosome molecular markers using RAPDs and fluorescent in situ hybridization in rainbow trout. Genetica, 101, 209-213.

KIRPICHNIKov, v. S. 1981. Genetic Bases of Fish Selection. Springer, Berlin.

MATSUDA, M., KUSAMA, T., OSHIRO, Y., KURIHARA, S. ET AL. 1997. Isolation of a sex chromosome-specific DNA sequence in the medaka, Oryzias latipes. Genes Genet. Syst., 72, 263-268.

MATSUDA, M., MATSUDA, S., HAMAGUCHI, S. AND SAKAIZUMI, M. 1998. Identification of the sex chromosomes of the medaka, Oryzias latipes, by fluorescence in situ hybridization. Cytogenet. Cell Genet., 82, 257-262.

MORAN, P., MARTINEZ, J. L., GARCIA-VAZQUEZ, E. AND PENDAS, A. M. 1996. Sex chromosome linkage of 5S rDNA in rainbow trout (Oncorhynchus mykiss). Cytogenet. Cell Genet., 75, $145-150$.

NAKAYAMA, I., FORESTI, F., TEWARI, R., SCHARTL, M. ET AL. 1994. Sex chromosome polymorphism and heterogametic males revealed by two cloned DNA probes in the $\mathrm{ZW} / \mathrm{ZZ}$ fish Leporinus elongatus. Chromosoma, 103, 31-39.

ohno, s. 1967. Sex Chromosomes and Sex-Linked Genes. Springer Verlag, Berlin.

Oliveira, C., FORESTI, F., Rigolino, M. G. AND tABATA, Y. A. 1995. Synaptonemal complex analysis in spermatocytes and oocytes of rainbow trout Oncorhynchus mykiss (Pisces, Salmonidae): the process of autosome and sex chromosome synapsis. Chromosome Res., 3, 182-190.

PARAN, I. AND MICHELMORE, R. W. 1993. Development of reliable PCR-based markers linked to downy mildew resistance genes in lettuce. Theor. Appl. Genet., 85, 985-993.

PARSONS, J. E. AND THORGAARD, G. H. 1985. Production of androgenetic diploid rainbow trout. J. Hered., 76, 177-181. 
REED, K. M. AND PHILLIPS, R. B. 1995. Molecular characterization and cytogenetic analysis of highly repeated DNAs of lake trout, Salvelinus namaycush. Chromosoma, 104, 242-251.

THORGAARD, G. H. 1977. Heterogametic sex chromosomes in male rainbow trout. Science, 196, 900-902.

THORGAARD, G. H. 1983. Chromosomal differences among rainbow trout populations. Copeia, 1983, 650-662.

VAN EENENNAAM, A. L., VAN EENENNAAM, J. P., MEDRANO, J. F. AND DOROSHOV, S. I. 1996. Rapid verification of meiotic gynogenesis and polyploidy in white sturgeon (Acipenser transmontanus Richardson). Aquaculture, 147, 177-189.

WINKLER, F. M., DIAZ, N. AND ESTAY, F. 1995. Allozyme variation in three commercial strains of rainbow trout in Chile. Aquaculture, 137, 56.

YOUNG, W. P., WHEELER, P. A., CORYELl, V. H., KEIM, P. ET AL. 1998. A detailed linkage map of rainbow trout produced using doubled haploids. Genetics, 148, 839-850. 